\title{
Stereocontrolled synthesis as an enabling tool for the configurational assignment of marine polyketide natural products
}

\author{
Nelson Y. S. Lam and lan Paterson ${ }^{*[a]}$ \\ Dedicated to Varinder Aggarwal in celebration of the $20^{\text {th }}$ anniversary of the Bristol Synthesis Meeting
}

\begin{abstract}
Marine polyketide natural products represent a fertile area of chemical space for the continual discovery of promising drug candidates. Advancements in spectroscopic and computational techniques have allowed for the increasingly facile structural and stereochemical determination of these biologically active molecules. However, their inherent architectural complexity often precludes a complete assignment even by the most discerning isolation chemists. This Minireview highlights how carefully conceived synthetic plans, employing highly stereocontrolled reactions, have enabled the configurational assignment of several polyketide natural products.
\end{abstract}

\section{Introduction}

The marine environment accounts for over $70 \%$ of the Earth's total area and harbours a plethora of biodiversity. ${ }^{[1]}$ This breadth of marine flora and fauna impacts the chemical diversity of secondary metabolites that many of these organisms produce. In facing the inherent problem of achieving efficacy in high dilution, many of these secondary metabolites produced by marine organisms have evolved over time to be highly potent binders of specific biological targets, or incredibly toxic defence mechanisms towards other living organisms. ${ }^{[2]}$

Throughout history, humankind's interdependence with nature has led to the extensive use of terrestrial natural products in treating diseases and ailments. ${ }^{[3]}$ Largely owing to their comparative inaccessibility, marine natural products have only recently started to enter the medicinal repertoire. ${ }^{[4]}$ Though marine natural products research has lagged behind that directed at terrestrial compounds, over 20,000 marine natural products have been discovered in the last 50 years. ${ }^{[5]}$ Indeed, their diverse range of bioactivities have resulted in the clinical validation of many promising compounds. ${ }^{[6]}$ Underpinning further discovery, however, is the successful structural elucidation of these compounds of interest. In order to be realised as clinical candidates, or for any further activity-guided structural optimisation to occur, their 2D and 3D molecular architecture must be unambiguously determined. This is by no means straightforward, given the complex stereostructures associated with many marine polyketide natural products, underscored by an elaborate isolation procedure that often only generates meagre amounts of the novel compound from a huge amount of

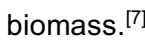

[a] N. Y. S. Lam, Prof Dr I. Paterson

University Chemical Laboratory

Lensfield Road, Cambridge, CB2 1EW, United Kingdom

Email: ip100@cam.ac.uk

Homepage: http://www-paterson.ch.cam.ac.uk/
As such, natural product isolation chemists are often faced with the daunting task of determining the structure of a complex compound and ascertaining its biological activity, all from miniscule amounts of material. In the past, with limited experimental data, the unambiguous structural elucidation was often only achieved through X-ray diffraction studies of single crystals of the natural product or derivative. Nowadays, complex molecular structures can be solved routinely by chemists employing an array of spectroscopic (especially NMR) techniques, where previously this may have taken many years to achieve ${ }^{[8]}$ It is no surprise that the overall advancement in natural product research has evolved symbiotically with advances in characterisation techniques, such that it is now possible to fully solve a structure with ever smaller amounts of pure compound. In particular, advances in long-range NMR techniques, ${ }^{[9]}$ along with detailed conformational analyses from the interpretation of coupling constant data of these molecules ${ }^{[10]}$ can be used synergistically to reveal the relative configuration of a novel chemotype.

Nelson Lam is a graduate of the University of Auckland, where he completed a double degree in BMus and BSc (Hons), completing his Honours project with Prof Christian Hartinger in 2014. He recently completed his postgraduate studies at the University of Cambridge (2019) under the supervision of Prof lan Paterson as a Woolf Fisher Scholar. During his PhD, he worked on the synthesisenabled assignment of stereochemically ambiguous polyketide natural products. $\mathrm{He}$ is

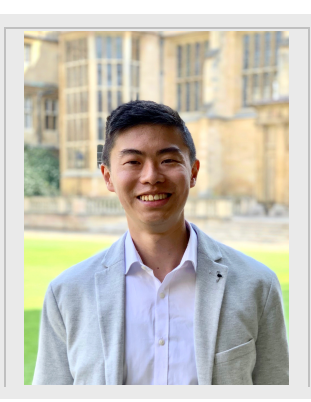
currently pursuing postdoctoral research with Prof Jin-Quan $\mathrm{Yu}$ at the Scripps Research Institute, California, as a Lindemann Fellow.

lan Paterson received his BSc (Hons) degree from the University of St Andrews and $\mathrm{PhD}$ from the University of Cambridge, working with Prof lan Fleming. After a postdoctoral period with Prof Gilbert Stork at Columbia University, he joined the faculty at University College London. In 1983, he returned to Cambridge, where he is now Professor of Organic Chemistry and a Fellow of Jesus College. His research interests are centred on novel synthetic methods for the efficient control of stereochemistry and the total

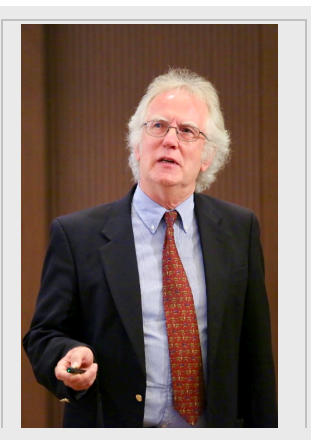
synthesis of bioactive natural products, particularly anticancer agents. His 
research achievements have been recognised by various awards, and he is a Fellow of the Royal Society and the Royal Society of Edinburgh.

However, these inferential experimental techniques are often insufficient to allow for a full structural determination with complete confidence. To alleviate these problems, many state-ofthe-art computational techniques, such as the DP4 NMR algorithm, ${ }^{[11]}$ have been developed to allow the application of statistical methods in assigning the most likely candidate structures for a natural product. Beyond this, recent advances in cryo-electron microscopy $(E M)^{[12]}$ have meant that these techniques are becoming more relevant for small molecules, rather than large biomolecules for which they have already found a niche. In the realm of natural products research, the increased ease of genome mining has allowed for the use of DNA sequence information to help identify the specific enzymes that catalyse similar reactions in related compounds, which can often aid in the structural elucidation of natural products. ${ }^{[13]}$

These aforementioned contemporary structural elucidation tools do not provide all the solutions and ab initio computational methods, including DP4, become prohibitively costly to run on large and especially flexible molecules; ${ }^{[11]}$ the nascent cryo-EM technology for small molecules relies on the sample being a solid and available in reasonable quantities often not feasible after an isolation campaign; ${ }^{[12]}$ and the use of bioinformatics as a prospective tool, requires the characterisation of the gene sequence encoding the biosynthetic machinery, itself a formidable task, especially when the actual producing organism may be highly elusive. ${ }^{[14]}$ Even then, these techniques are seldom able to fully rationalise the complete stereochemistry of a natural product. For these reasons, a targeted synthesis campaign still remains the undisputed arbiter of structural proof. Beyond chemical derivitisation and degradation, a total synthesis of a natural product followed by its spectroscopic comparison with the natural sample gives an unambiguous proof of a compound's overall constitution and 3D structure.

\section{The role of synthesis in the stereochemical (mis)assignments of complex marine polyketide natural products}

As spectroscopic characterisation techniques become more advanced and the analytical toolkit becomes more sophisticated, it should logically follow that stereochemical assignment errors should accordingly decrease. Interestingly, however, taking what arguably is the most powerful tool for characterisation - the NMR spectrometer, the continual enhancement of an NMR magnet's field strength over the last few decades correlates positively to the absolute number of misassignments reported in the literature. ${ }^{[15]}$ This seemingly contradictory observation indicates that the improvement in sensitivity does not fundamentally alter how analyses are conducted. Rather than increasing the accuracy of the data analysis and spectroscopic assignments, the correlation is attributed to better spectrometers enabling the elucidation of increasingly limited amounts from extracts, leading to a greater number of new marine and terrestrial natural products isolated. ${ }^{[15]}$
Additionally, these structural misassignments often reflect on the inherent limitations of each technique, some of which cannot be resolved even if a combination of techniques are used. ${ }^{[8]}$ By way of example, eventhe seemingly infallible $\mathrm{X}$-ray crystallographic technique has its drawbacks. For example, crystallographic techniques often struggle to discern between atoms that do not contain hydrogen atoms; a fact that led to the structural misassignment of the antibiotic kinamycin $C(1$, Figure 1$){ }^{[16]}$

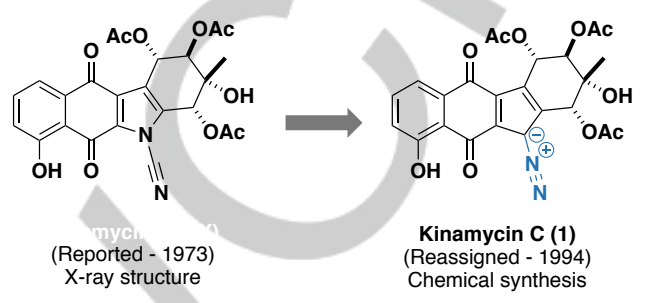

Figure 1. Originally reported and revised structure for kinamycin (1)

In these cases, the nature of inferential structural elucidation methods, such as NMR spectroscopy, can be limited in its ability to definitively resolve stereochemical ambiguities, as a diverse set of isomeric candidates could plausibly be accounted for by the same set of spectra. ${ }^{[17]}$ Moreover, the assignment of absolute configuration usually requires derivitisation such as by application of the modified Mosher method. ${ }^{[18]}$ Because of this, comparative methods enabled by targeted synthesis remain as the crowning method for stereochemical determination. The power of synthesis shines through when discerning between diastereomers, especially ones containing distal stereoclusters. In cases where the molecule is particularly flexible, ab initio NMR methods often cannot generate sufficiently confident answers for which structures are likely to be correct, as the plurality of low energy conformers often precludes accurate NMR predictions. ${ }^{[11]}$ In these cases, the unambiguous stereochemical assignment of a natural product is usually achieved through its total synthesis. Prominent examples in which the total synthesis of a compound has resulted in their structural reassignment include the marine natural products callipeltoside A (2, Figure 2) by Paterson ${ }^{[19]}$ and Trost, ${ }^{[20]}$ and azaspiracid-1 (3, Figure 3 ) by Nicolaou $(3 \mathbf{a})^{[21]}$ and Forsyth (3b). ${ }^{[22]}$

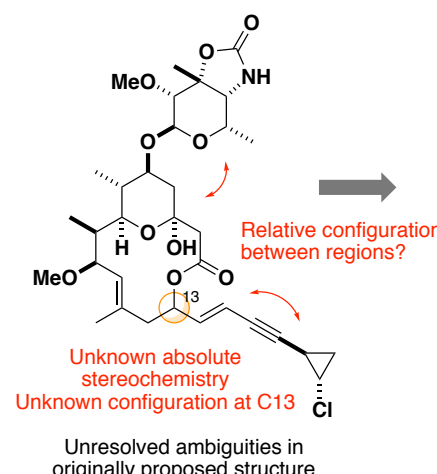

originally proposed structure

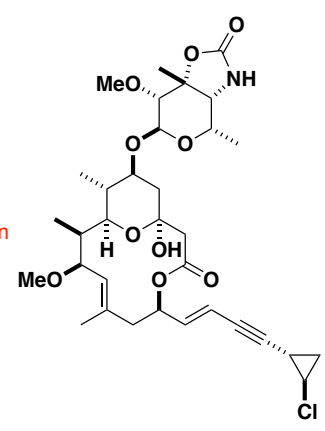

Callipeltoside A (2) Confirmed by total synthesis
Figure 2. Originally reported and revised structure for callipeltoside A (2) 
These synthesis-enabled assignments and reassignments have continued to the present day; a cursory search on a literature database containing the terms "synthesis" and "stereochemical revision/reassignment" generated over 30 results from January 2016 until the present (August 2019), across a wide range of terrestrial and marine natural products. This Minireview highlights the prominent role synthesis has played in the stereochemical elucidation of a selection of five marine polyketide natural products performed in the Paterson group: dolastatin 19, dictyostatin, leiodermatolide, phormidolide $\mathrm{A}$ and hemicalide.
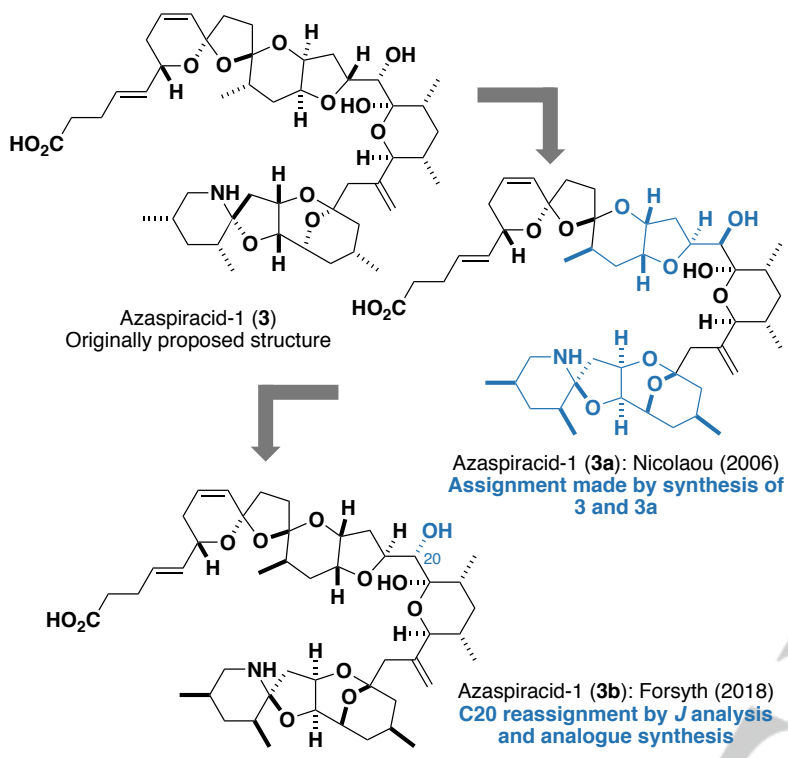

Figure 3. Originally reported and revised structures for azaspiracid-1

\subsection{Synthesis and configurational alignment with analogous polyketide natural products enables the reassignment of dolastatin 19 and dictyostatin}

The intricacies of polyketide biosynthesis mean that structurally similar scaffolds are likely to share a common biosynthetic origin. The ability to recognise similar patterns and features with related congeners or a 'biogenesis-guided' elucidation can be a powerful tool in the assignment of complex polyketide architectures. Here, two examples from our group are presented to demonstrate how a recognition of structurally similar features in related marine polyketides led to the configurational reassignment of dolastatin 19 and dictyostatin, which were ultimately proven through their total syntheses.

The sea hare Dolabella auricularia affords a wide range of bioactive natural products, including the 14-membered macrolides aurisides $\mathrm{A}$ and $\mathrm{B}$, and the highly cytotoxic peptides dolastatins 10 and 15. In 2004, the Pettit group isolated dolastatin 19 (4, Figure 4), ${ }^{[23]}$ a highly active polyketide from the same marine organism. The originally proposed structure for dolastatin 19 was determined through extensive NMR spectroscopic analysis by the isolation group, which revealed a similar chemotype to the callipeltosides (vide supra) and aurisides. ${ }^{[23]}$
Contrary to these related natural products, however, was the recognition that the reported structure for dolastatin 19 was epimeric across $\mathrm{C} 5-\mathrm{C} 7$ and $\mathrm{C} 13$, which appeared to be anomalous with regards to the anticipated common biogenesis of these polyketides by the likely cyanobacteria producing organism. ${ }^{[24]}$

To probe the stereochemical inconsistencies with related congeners, imolecular modelling studies with the macrocyclic aglycon variants of the aurisides, callipeltosides and dolastatin 19 were conducted. This indicated that both the aurisides and the callipeltosides adopted a chair conformation for the hemiacetal region, whereas the originally proposed structure for dolastatin 19 adopted a highly distorted boat conformation for the same region. ${ }^{[24]}$ These empirical observations alongside the common biosynthesis hypothesis led us to putatively reassign the stereostructure of dolastatin 19 to $\mathbf{4 a}$, which then needed to be unambiguously supported through a total synthesis. To do this, the macrolide was disconnected via a late-stage glycosylation and macrolactonisation to reveal the seco precursor. This linear fragment $\mathbf{5}$ could then be expeditiously constructed by a series of aldol reactions to configure most of the stereocentres.

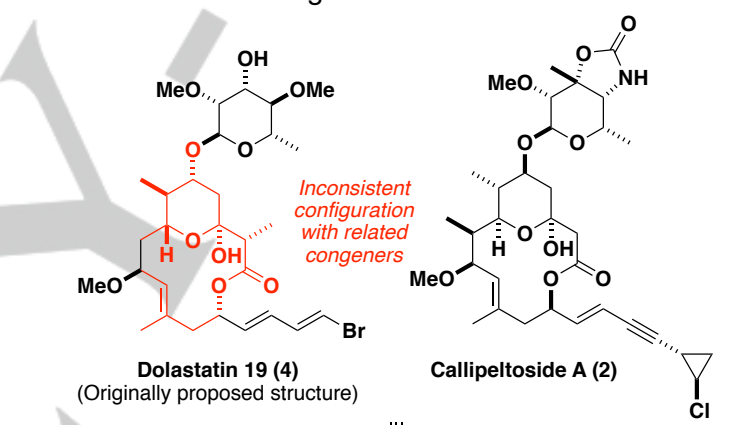

Open chain seco form $\quad||$
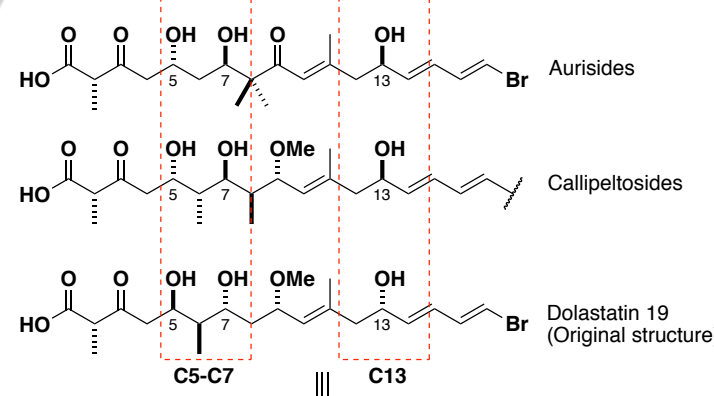

$\mathrm{OH}$

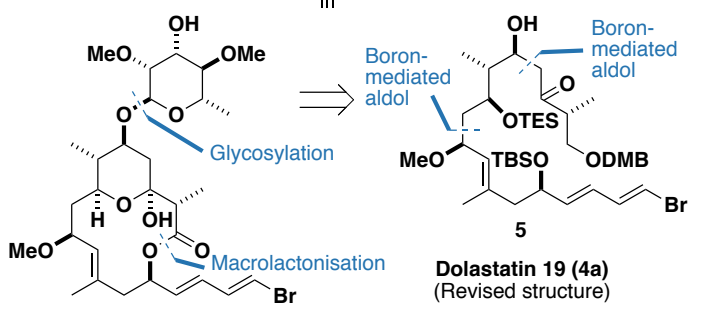

Figure 4. Originally proposed (4) and reassigned structure (4a) for dolastatin 19 , highlighting the structural homology with related marine macrolides

The synthesis of dolastatin 19 commenced with a titaniummediated asymmetric vinylogous Mukaiyama aldol reaction 
between $\mathbf{6}$ and $\mathbf{7}$ to generate adduct $\mathbf{8}$ (Scheme 1). ${ }^{[25]}$ Subsequent manipulation then gave aldehyde $\mathbf{9}$, which was subjected to a 1,4syn boron-mediated aldol reaction ${ }^{[26]}$ with ketone $\mathbf{1 0}$ to give $\mathbf{1 1}$. After engaging in a 1,3-syn reduction and silyl protection, fragment 12 was elaborated to aldehyde 13 in anticipation of the third boron-mediated aldol reaction with ketone 10 , which gave the full carbon skeleton $\mathbf{5}$ of dolastatin 19 with excellent diastereoselectivity. From here on, elaboration to the required aglycon 14 was attained, which allowed for an interim NMR comparison with the natural product and gave an early indication of the validity of the proposed reassignment. A final glycosylation with 15 followed by silyl deprotection then gave the corrected structure $4 a$ for dolastatin 19, which matched the spectroscopic data reported for the natural product. Further evidence in support of the reassignment included the close agreement of the measured specific rotation, in addition to its comparable level of cancer cell growth inhibition compared with that originally reported by the Pettit group. The total synthesis of dolastatin 19 (4a), as enabled by our highly stereoselective aldol methodology, then secured an unambiguous verification of our biogenesisguided structural reassignment.

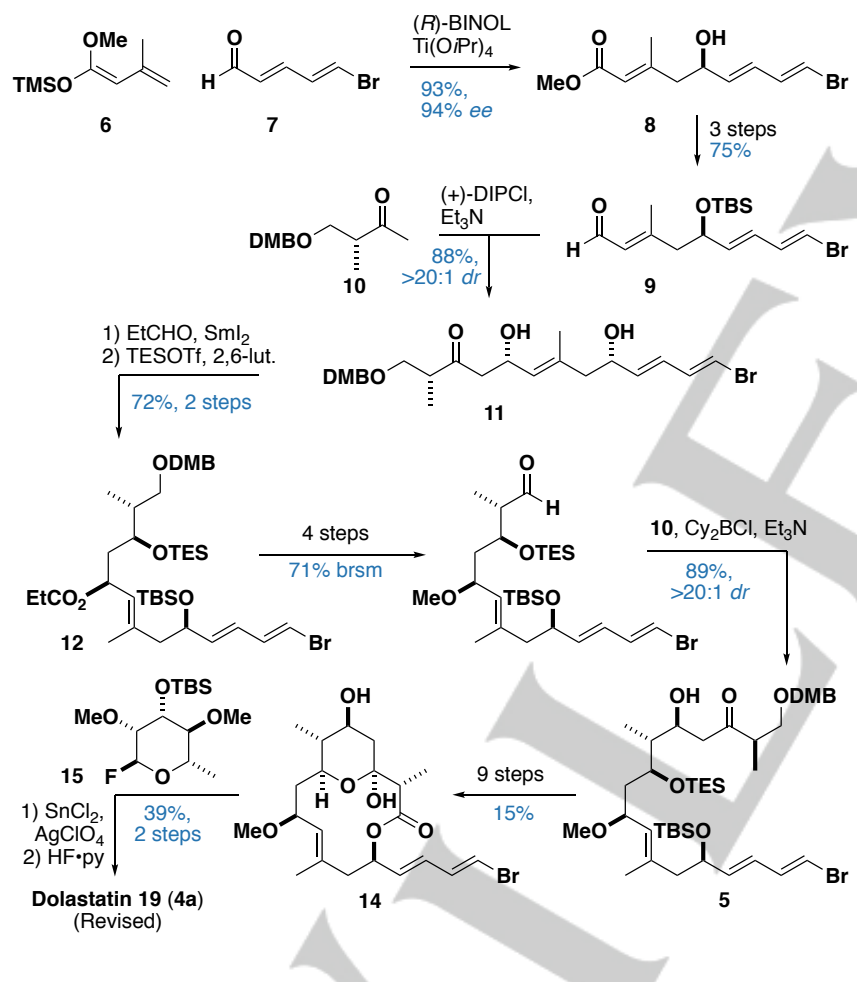

Scheme 1. The total synthesis of dolastatin 19, which confirmed the stereochemical reassignment in $\mathbf{4 a}$

In 1994, the Pettit group reported the isolation of the marine macrolide dictyostatin (16, Figure 5) from an Indian Ocean sponge and demonstrated that it displayed potent cancer cell growth inhibition at $\mathrm{nM}$ concentrations. ${ }^{[27]}$ At the time of its first isolation, the planar 22-membered macrolide structure was reported. However, inconclusive evidence was given for the partial assignment of its stereochemistry. Dictyostatin exhibited potent cytotoxicity, even against multidrug-resistant cancer cell lines, and represented a highly promising lead as a cancer chemotherapeutic agent; all attractive features that led us to embark on our synthetic campaign.

Following the reisolation of dictyostatin by Wright at the Harbor Branch Oceanographic Institution, we determined the relative configuration as indicated in $\mathbf{1 6 a}$ through a combination of J-based coupling constant analysis and extensive NOE experiments. ${ }^{[28]}$ Guided by the striking structural homology between the two microtubule-stabilising agents dictyostatin and discodermolide (17), it was conjectured that there was likely to be a common biogenesis for these polyketides, such that the absolute configuration for dictyostatin was putatively assigned as in $16 \mathrm{a}$.

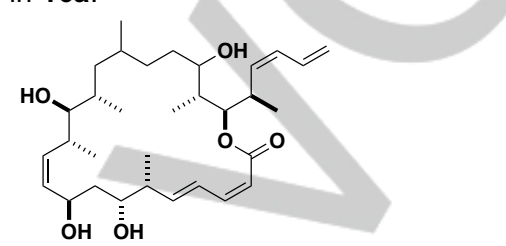

Dictyostatin (16) Original reported structure Pettit (1994)

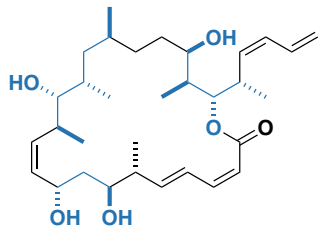

Dictyostatin (16a) (Revised structure) Paterson (2004)<smiles>C=C/C=C\[C@H](C)[C@H](OC(N)=O)C(C)C(O)[C@H](C)C/C(C)=C\[C@H](C)[C@@H](O)C(C)/C=C\C(O)CC1OC(=O)C(C)[C@H](O)[C@H]1C</smiles>

Discodermolide (17)

Figure 5. Originally proposed (16) and revised structure for dictyostatin (16a), highlighting its structural homology with discodermolide (17)

We commenced our synthetic campaign by elaborating diol 18 to iodide 19, which underwent a Myers alkylation ${ }^{[29]}$ with the lithium enolate of $\mathbf{2 0}$ to afford $\mathbf{2 1}$ (Scheme 2). ${ }^{[30]}$ Further manipulation gave aldehyde 22, which was subjected to an HWE olefination with phosphonate 23 to generate 24. A further sequence then afforded the northern hemisphere fragment $\mathbf{2 5}$, bearing an aldehyde functionality in anticipation of the planned Still-Gennari olefination ${ }^{[31]}$ with the southern hemisphere fragment.

The synthesis of the southern fragment commenced with a Brown asymmetric crotylation ${ }^{[32]}$ of 26 to give 27. A further sequence then gave the Still-Gennari type phosphonate $\mathbf{2 8}$, which underwent an HWE olefination to give 29 with good levels of $Z$ selectivity. From here, elaboration by Stille coupling with stannane 30, macrolactonisation, Luche reduction and global deprotection afforded synthetic dictyostatin (16a), which proved to be identical in all respects to an authentic natural sample. Our successful total synthesis, alongside that achieved concurrently by the Curran group, ${ }^{[33]}$ enabled the unambiguous corroboration of the proposed stereochemical assignment. This supported our hypothesis for its common biogenesis to discodermolide, and subsequently made possible its evaluation as both a potential anticancer agent ${ }^{[34]}$ and a neuroprotective agent. ${ }^{[35]}$ 


$$
\text { (MeO) }
$$

Scheme 2. The total synthesis of dictyostatin, which confirmed the relative and absolute configuration of the natural product as $\mathbf{1 6 a}$

\subsection{Synthesis provides the ultimate proof of configuration of leiodermatolide from four candidate stereoisomers}

While being the most powerful spectroscopic technique in structural elucidation, NMR-based methods often have their limitations in the confident configurational assignment of stereocentres. In particular, compounds bearing distally related stereocentres often lead to inconclusive assignments. This was particularly evident in our synthetic campaign towards leiodermatolide (31, Figure 6), a highly potent cytotoxic polyketide patented by Wright et al. in 2008. ${ }^{[36]}$

In collaboration with the Wright group, we employed extensive NMR spectroscopic analysis to separately elucidate the configuration of the C6-C9 and C14-C15 regions, contained within the 16-membered macrolactone, along with the C21-C25 stereocluster. ${ }^{[37]}$ The proposed relative configuration of the complete macrocycle was then supported by the computational DP4 NMR method developed by Smith and Goodman, ${ }^{[11]}$ which assigned the macrocyclic diastereomer denoted in Figure 6 with $>99 \%$ probability, and the $\mathrm{C} 21-\mathrm{C} 25$ region with $>99 \%$ probability. However, owing to the spatially distal nature between the C1-C15 macrocycle and the $\mathrm{C} 21-\mathrm{C} 25$ region, a conclusive assignment could not be made between these two regions. This was not resolved upon forming the $\mathrm{C} 7, \mathrm{C} 21$ bis Mosher esters, which gave inconsistent $\Delta \delta s R$ signs. Overall, these combined initial efforts towards the stereochemical elucidation of (-)-leiodermatolide were narrowed down to considering four candidate stereoisomers.

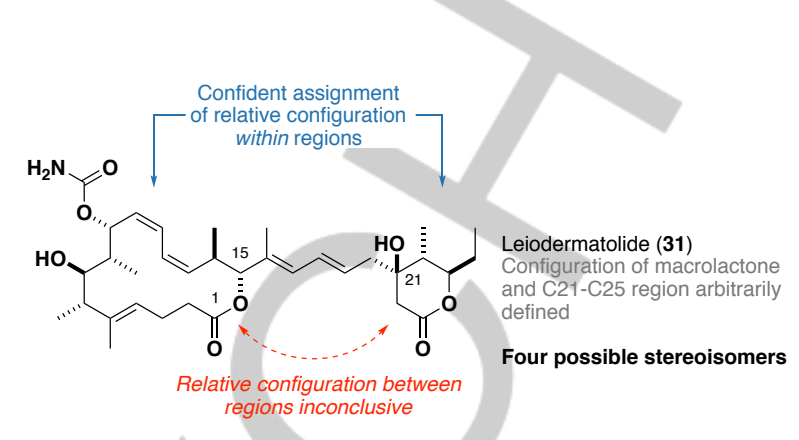

Figure 6. Structure of leiodermatolide (31). The relative configuration between the macrolactone and the $\mathrm{C} 21-\mathrm{C} 25$ region is arbitrarily defined

Our synthetic effort began with targeting the leiodermatolide macrocycle. ${ }^{[38]}$ Starting with ketone $\mathbf{3 2}$ and aldehyde 33, a DIPOTf-promoted boron-mediated aldol reaction, ${ }^{[39]}$ followed by Evans-Tischenko reduction ${ }^{[40]}$ and protection configured all four stereocentres present in the C6-C9 region (34, Scheme 3). A further 11 steps were required to generate the C1-C11 stannane 35. The remaining fragment was synthesised from ketone 36 . A boron-mediated aldol reaction with aldehyde 37 set the C14-C15 configuration in $\mathbf{3 8}$. Following further manipulation, this gave dihalide 39 and stannane 35 , which underwent a site-selective Stille cross coupling to generate $\mathbf{4 0}$. Progression to the seco acid 41 was followed by macrolactonisation and carbamate installation, generating the 22-membered macrocycle 42 . The close ${ }^{1} \mathrm{H}$ and ${ }^{13} \mathrm{C}$ NMR correlation with leiodermatolide provided further support for the relative configuration of the macrocycle. However, the (+)sign of the specific rotation recorded for $\mathbf{4 2}$ was opposite to that recorded for (-)-leiodermatolide, tentatively suggesting that the synthesis should be retargeted in the enantiomeric series. ${ }^{[41]}$ During this time, the Fürstner group reported a total synthesis of both candidate diastereomers of leiodermatolide, giving a synthetic proof of the relative configuration between the $\mathrm{C} 1-\mathrm{C} 15$ macrocycle and the $\mathrm{C} 21-\mathrm{C} 25$ region. ${ }^{[42]}$ The comparison between the two diastereomers was only made possible through subtle peak shape differences in the ${ }^{1} \mathrm{H}$ NMR spectra, leading to their synthesis-enabled stereochemical assignment. Additionally, the Fürstner synthesis of the correct diastereomer of leiodermatolide also matched the specific rotation data, establishing the absolute configuration for (-)-leiodermatolide as shown in ent-31.

Our initial forays towards the leiodermatolide macrocycle and the Fürstner group's timely efforts gave credence towards the assignment of the absolute configuration of (-)-leiodermatolide. The key lessons learnt from synthesising the macrocycle then allowed us to develop a more efficient second-generation route towards (-)-leiodermatolide, achieving its total synthesis in 23 steps and $3.2 \%$ overall yield. ${ }^{[43]}$

Leiodermatolide stands as a testament towards the combined power of experimental NMR and computational methods in aiding the stereochemical assignment of complex polyketide natural products. However, even this has its limitations, especially with distally related stereoclusters. The final 
assignment of configuration ultimately rested upon its successful total synthesis, demonstrating once again the role synthesis plays as the ultimate arbiter of structure.

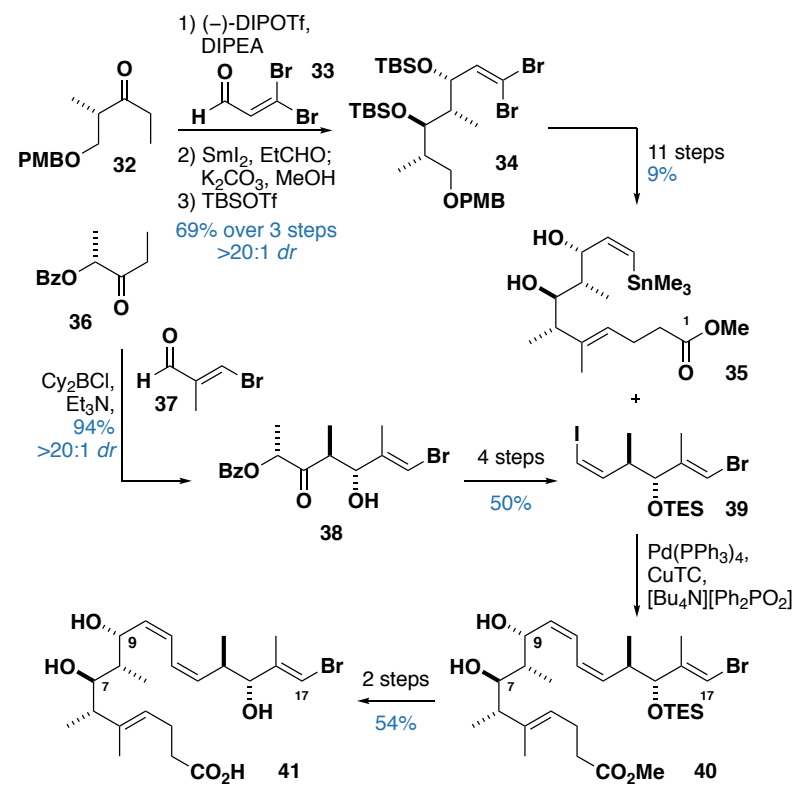

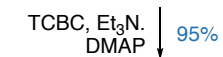

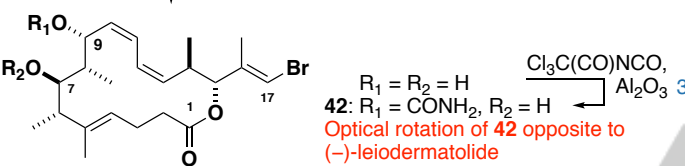

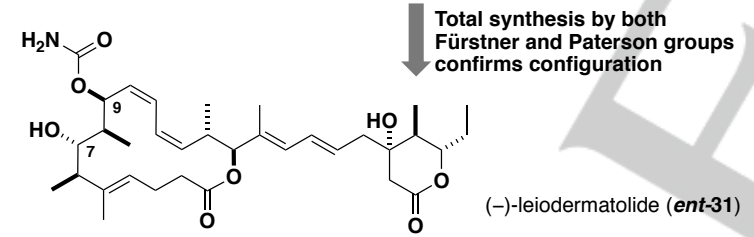

Scheme 3. Synthesis of the macrocyclic core of (-)-leiodermatolide $\mathbf{4 2}$, which gave the contrasting chiroptical data as compared with the natural product

2.3. A serendipitous outcome from a vinyl Grignard aldehyde addition leads to the stereochemical reassignment of phormidolide $A$

Occasionally, misassignments can still arise due to the stereochemical complexity of the natural product that are not ameliorated by advances in characterisation techniques. Phormidolide $A$ is an example of this. In the initial isolation report by the Gerwick group, a comprehensive elucidation of its 3D structure was described ${ }^{[44]}$ which was apparently corroborated by its biosynthesis in a subsequent paper. ${ }^{[45]}$ During our ongoing synthetic campaign in collaboration with the Britton group towards this intriguing polyketide, a combination of an unexpected reaction outcome and its subsequent investigation led to the configurational reassignment of phormidolide $A$.
Phormidolide A (43, Figure 7) was isolated from the marine cyanobacteria Leptolyngbya $\mathrm{sp}$. collected off the coast of Sulawesi, Indonesia. Interestingly, phormidolide A was found to be inactive in the National Cancer Institute $(\mathrm{NCl})$ in vitro 60 -cell line assay, though it did exhibit potent brine shrimp toxicity (LD50 $=1.5 \mu \mathrm{M}$ ). It was surmised that phormidolide $\mathrm{A}$ may have an adaptive significance for the organism, perhaps playing a role in deterring predators. ${ }^{[44]}$ At the time, the proposed 3D structure of phormidolide A was wholly determined by NMR methods via $\mathrm{J}$ based coupling constant analysis as well as by the preparation of the triacetonide derivative 44. At the outset of our synthesis campaign, we recognised that the original J-based coupling constant analysis contained several inconsistencies, notably providing inconclusive evidence for assigning the relative configuration between the $\mathrm{C} 1-\mathrm{C} 17$ macrolactone and the C18C33 side chain. As the assigned absolute configuration of the macrocycle was deemed secure from Mosher ester analysis, the two enantiomeric forms of the side chain were targeted to probe the relative configuration to the macrolactone.

Relative configuration between
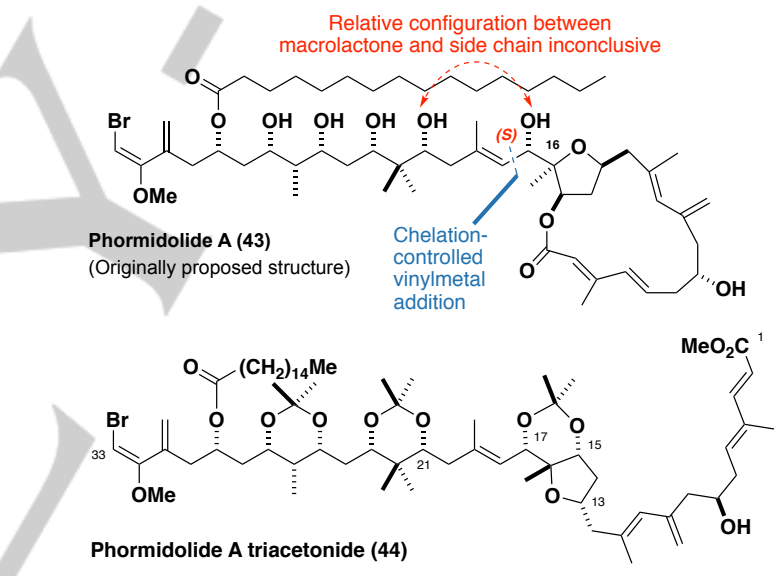

Figure 7. Proposed structure (43) of phormidolide A and its triacetonide derivative $\mathbf{4 4}$

Hypothesising that the reported $\mathrm{C} 17$ configuration could be installed via a chelation-controlled vinylmetal addition to a suitable THF aldehyde, disconnection across the $\mathrm{C} 17-\mathrm{C} 18$ bond revealed the $\mathrm{C} 1-\mathrm{C} 17$ macrolactone, and a truncated side chain fragment affording the C18-C23 vinyl iodide as the planned vinylmetal precursor. ${ }^{[46]}$ Starting from aldehyde $\mathbf{4 5}$ and ketene silyl acetal $\mathbf{4 6}$, an asymmetric Mukaiyama aldol reaction using a valine-derived oxazaborolidinone mediator ${ }^{[47]}$ gave enantioenriched 47 , with the absolute configuration dictated by the use of either D- or L-valine (Scheme 4). From here, three more steps were required to give both enantiomers of the C18-C23 vinyl iodide $\mathbf{4 8}$ and ent-48. 


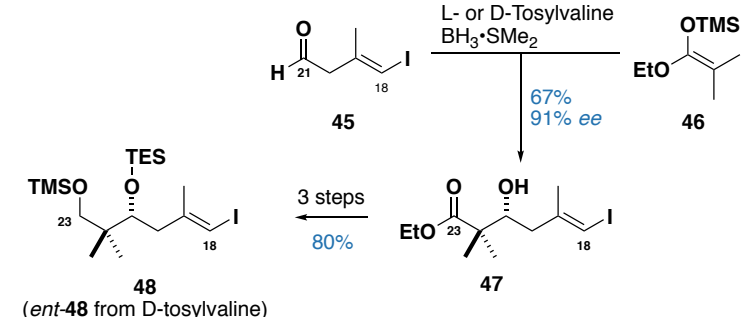

Scheme 4. Synthesis of the model side chain fragment $\mathbf{4 8}$ and ent-48

The macrolactone was similarly simplified, truncating it to a model $\mathrm{C} 10-\mathrm{C} 17$ aldehyde $\mathbf{4 9}$ bearing a dimethylacrylate ester as a surrogate for the macrolactone linkage. The synthesis of $\mathbf{4 9}$ commenced with an asymmetric L-proline-mediated aldol reaction $^{[48]}$ between aldehyde $\mathbf{5 0}$ and dioxanone $\mathbf{5 1}$ to afford chlorohydrin 52 (Scheme 5). A subsequent methyl Grignard addition followed by cyclisation of $\mathbf{5 3}$ gave the functionalised THF core 54, which was further manipulated to give the suitably configured intermediate $\mathbf{5 5}$. The $\mathrm{C} 15$ alcohol in $\mathbf{5 5}$ was then esterified with acid $\mathbf{5 6}$, followed by conversion into the model aldehyde $\mathbf{4 9}$ to investigate the vinylmetal addition. which gave the corresponding diacetonide 59b. Interestingly, NMR comparison of $\mathbf{5 9 a}$ and $\mathbf{5 9 b}$ (containing the reported $17 \mathrm{~S}$ configuration) with the triacetonide derivative 44 showed that $59 a$ bearing the epimeric $17 R$ configuration was in fact a very good match with 44! Here, a reanalysis of the original NMR data of phormidolide $\mathrm{A}$ and its triacetonide supported the conclusion that C17 was misassigned. To then probe whether or not the remainder of the side chain required reassignment, the analogous adduct 58c and its corresponding diacetonide 59c were synthesised. Detailed NMR comparison of $59 \mathrm{a}$ and $59 \mathrm{c}$ with phormidolide A triacetonide 44 revealed that diacetonide 59c, which contained the inverted $\mathrm{C} 17$ and $\mathrm{C} 21$ configuration, best matched the natural product, resulting in a reassignment of seven of the 11 stereocentres in phormidolide A (43a, Figure 8).

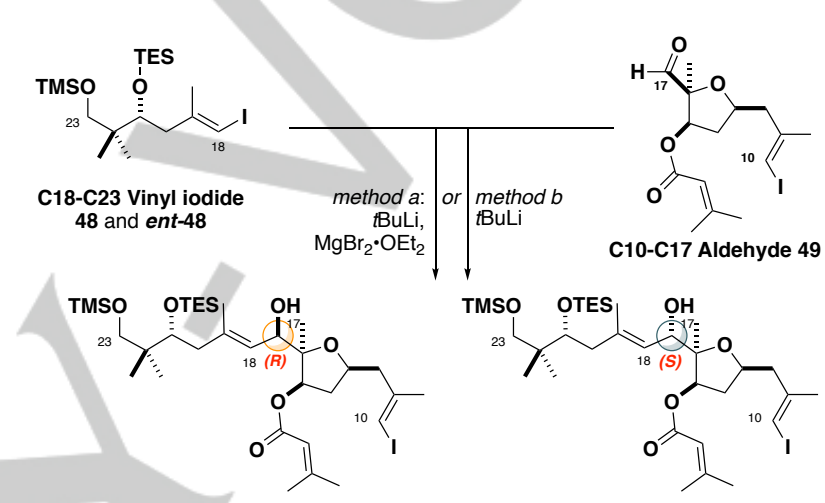

58a (from method a with 48)

$58 b$ (from method b with 48 )

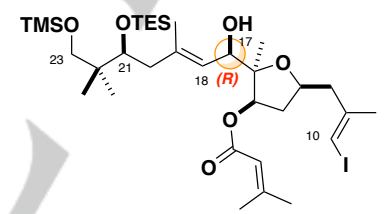

58c (from method a with ent-48)
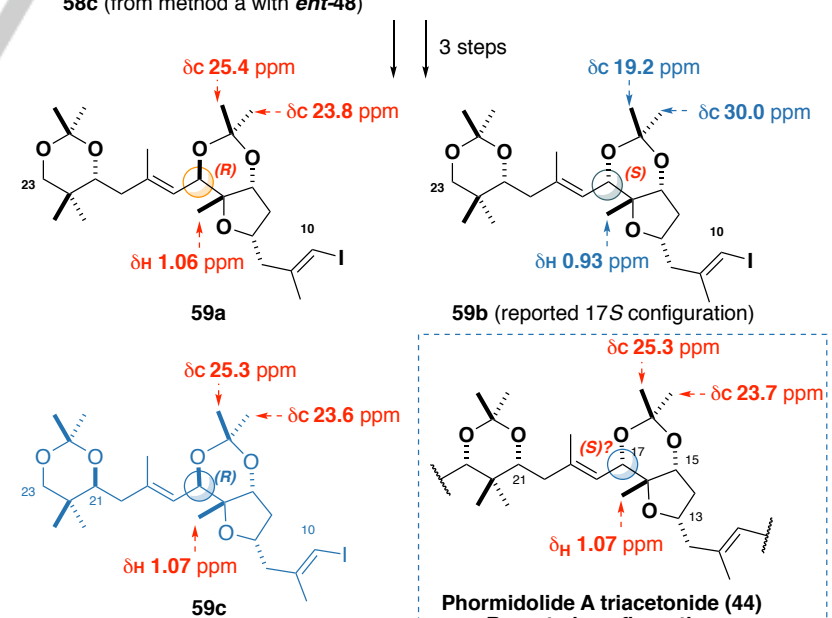

59b (reported $17 S$ configuration)

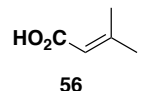

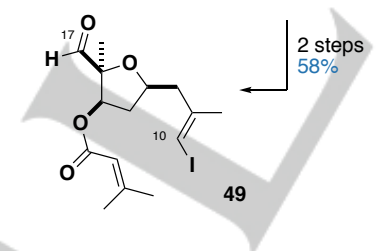

Scheme 5. Synthesis of the model aldehyde $\mathbf{4 9}$

Vinyl iodide 48 was transformed to the corresponding Grignard reagent and a chelation-controlled addition with $\mathrm{MgBr}_{2} \cdot \mathrm{OEt}_{2}$ into aldehyde 49 was conducted (Scheme 6). The stereochemistry of the resulting adduct $\mathbf{5 8}$ a was then determined by conversion into the corresponding diacetonide $59 a{ }^{[49]}$ which surprisingly bore the $17 R$ configuration, epimeric to the expected $17 S$ configuration required for phormidolide $A$. The sense of stereocontrol arising from chelation was confirmed by omitting the addition of $\mathrm{MgBr}_{2} \cdot \mathrm{OEt}_{2}$. This delivered predominantly the epimeric $17 S$ configuration in $\mathbf{5 8} \mathbf{b}$ arising from polar Felkin-Anh control,
Scheme 6. Synthesis of the diastereomeric diacetonides $59 a-c$ revealed $59 \mathrm{c}$ being the best match with phormidolide $A$ triacetonide 44

This reassignment was particularly notable in light of the fact that the biosynthesis for phormidolide A was previously 
reported. ${ }^{[45]}$ In this study, the stereochemistry for phormidolide A was hypothesised to be set by the action of ketoreductase enzymes. In the originally proposed structure (43) of phormidolide A, all carbinol stereocentres are L-configured (Figure 8). This contradicts the assignment predicted by the ketoreductase sequences, which based on analogous ketoreductases indicates that they should likely be D-configured. Our synthesis-based detective work reassigns these L-configured carbinol centres to their corresponding D-configuration in 43a, which now better rationalises the stereochemistry of phormidolide $A$. This example neatly highlights the decisive role synthesis can play in the unambiguous stereochemical assignment of complex polyketide natural products.

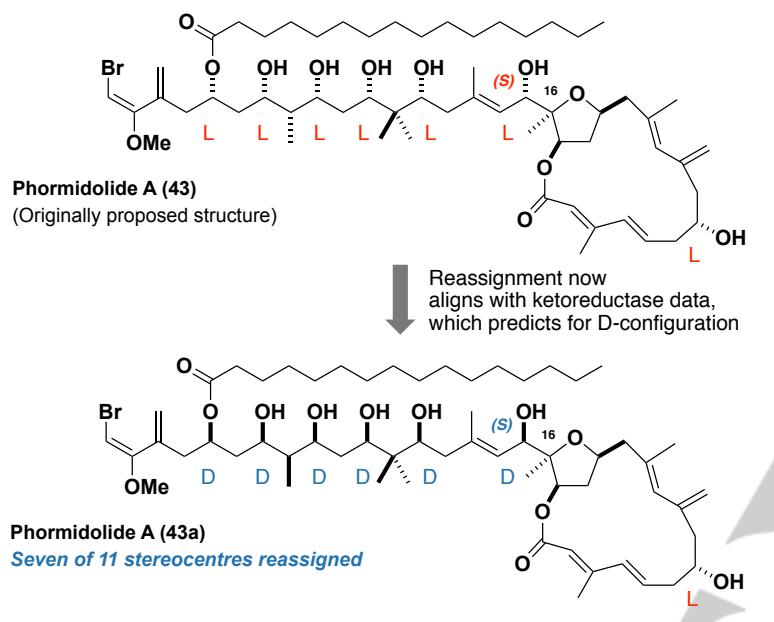

Figure 8. The reassigned structure of phormidolide A (43a) now more closely aligns with the ketoreductase data presented by the Gerwick group. ${ }^{[45]}$

2.4. A combination of synthesis and computational methods enables the ongoing stereochemical elucidation of hemicalide

The continual advances in computational NMR methods has resulted in its increasing uptake to assist in structural elucidation. As illustrated with leiodermatolide, the DP4 parameter introduced by Smith and Goodman ${ }^{[11]}$ successfully allowed for the corroboration of the macrocyclic stereochemistry in leiodermatolide. More recently, the Aggarwal group demonstrated just how powerful a synergistic combination of computational methods and synthesis is in their landmark stereochemical elucidation of the baulamycins. ${ }^{[50]}$ In this final example, we demonstrate that it is through combination of synthesis and computational NMR methods that we were able to successfully tackle a seemingly intractable number of stereoisomers presented by the natural product hemicalide.

First appearing in the patent literature in 2011 , hemicalide (60, Figure 9) was isolated from the marine sponge Hemimycale sp. collected around the Torres Islands of Vanuatu by CNRSPierre Fabre Laboratories and the Institut de Recherche pour le Développement. ${ }^{\left[{ }^{[1]}\right.}$ Preliminary biological studies on hemicalide revealed its extraordinary biological activity, registering $\mathrm{pM}$ levels of cytotoxicity across a panel of cancer cell lines. Initial characterisation revealed a 46-carbon skeleton possessing 21 stereocentres. Unfortunately, further derivatisation or degradation studies to ascertain both its relative and absolute configuration were not conducted, owing to the scarce supply of material, leaving all 21 stereocentres unassigned to produce $2^{21}$ (or over 2 million!) possible stereoisomers.

To simplify the task of ascertaining the relative configuration of hemicalide, the Ardisson and Cossy groups began by examining isolated stereoclusters, notably the C8-C13 polypropionate, ${ }^{[52]}$ the $\mathrm{C} 18-\mathrm{C} 24$ dihydroxylactone ${ }^{[53]}$ and the C36C46 hydroxylactone ${ }^{[54]}$ regions (Figure 9) and determining their likely configurations through the synthesis of model fragments, which resulted in the assignments shown in 61, 62 and 63. In collaboration with the Goodman group, we independently began tackling the stereoconundrum of hemicalide by targeting the same stereochemically rich regions through comparing $a b$ initio generated NMR chemical shifts of candidate diastereomers and calculating a probability for a confident assignment using the DP4 method. This study corroborated the assignments of the C8-C13 region $\mathbf{6 1}$ and the C36-C46 region $\mathbf{6 3}$, but returned the 18,19-syn configuration in $\mathbf{6 2 a}$ as the most likely candidate diastereomer $(99 \%)$ for the dihydroxylactone region, ${ }^{[55]}$ with the configuration shown in $\mathbf{6 2}$ as synthesised by Ardisson registering as highly improbable (1\%).

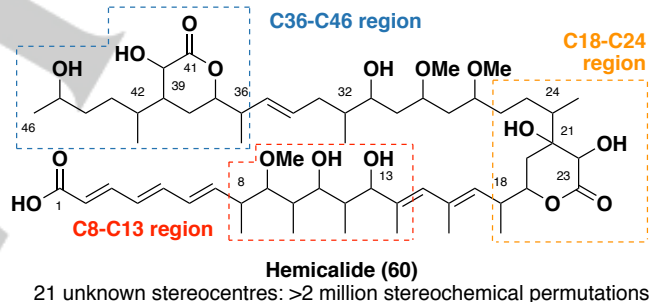

21 unknown stereocentres: $>2$ million stereochemical permutations

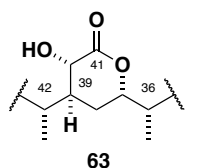

Assignment by Ardisson/Cossy

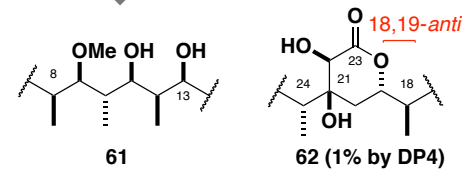

DP4 analysis

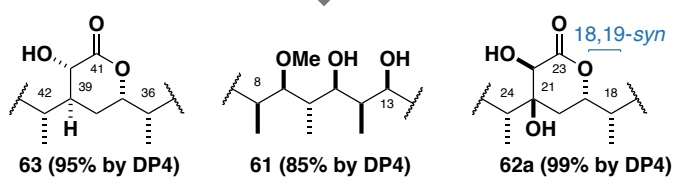

Figure 9. Planar structure of hemicalide (60), initial analysis by Ardisson/Cossy followed by DP4 studies conducted by the Paterson/Goodman groups resulting in the preliminary reassignment of 62 to $62 a$

In light of this incongruous result, we sought to corroborate the DP4 prediction through a targeted synthesis of a model dihydroxylactone truncate 63 (Scheme 7). This commenced with a DIPCl-mediated boron-mediated aldol reaction between aldehyde 64 and ketone 65 , both derived from the same enantiomer of Roche ester $\mathbf{6 6}$, to form adduct $\mathbf{6 7}$. A four-step 
sequence involving protection, aldol addition, lactonisation and dehydration afforded 68 . This could be dihydroxylated to install the final two stereocentres in fragment 69. At this point, a Stille cross-coupling with stannane $\mathbf{7 0}$ generated model fragment $\mathbf{6 3}$, containing the 18,19 -syn configuration, which gratifyingly gave a much closer spectroscopic match to the natural product than the original assignment proposed by Ardisson in $\mathbf{6 2}$.

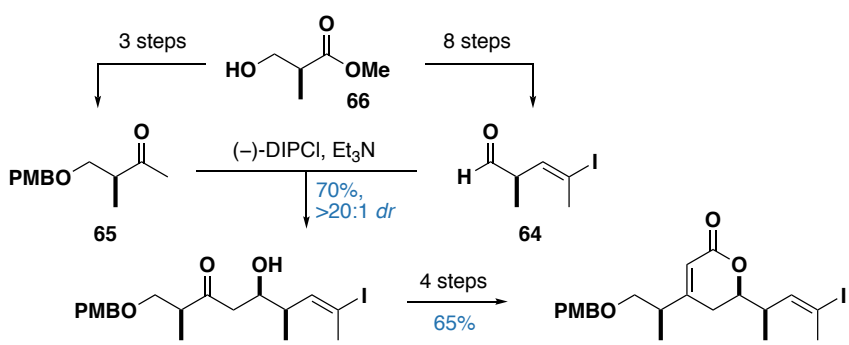
67

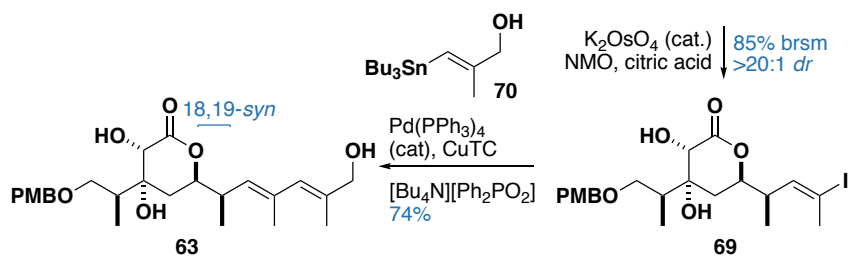

Scheme 7. Synthesis of model truncate $\mathbf{6 3}$ for NMR comparison revealed that hemicalide possesses the 18,19-syn configuration

So far, the combined work of the Ardisson/Cossy teams and ourselves has resulted in the elucidation of 16 out of the 21 stereocentres in hemicalide, leaving the $\mathrm{C} 27-\mathrm{C} 32$ region (four stereocentres) and the isolated C45 stereocentre unassigned. Additionally, the relative configuration between each stereocluster remains undetermined. The latter problem was initially probed computationally, but this was found to be impractical given the size and flexibility of the truncates in question. Therefore, we turned to synthesis to help solve this stereoconundrum. Specifically, we aimed to generate two candidate diastereomers for the $\mathrm{C} 1-\mathrm{C} 28$ fragment containing the $\mathrm{C} 1-\mathrm{C} 15$ region and the revised $\mathrm{C} 16-\mathrm{C} 24$ region. From intermediate ent-69, the completion of the $\mathrm{C} 16-\mathrm{C} 28$ fragment $\mathbf{7 1}$ required five steps (Scheme 8), ${ }^{[5]}$ and this was planned to undergo an analogous Stille coupling with a suitable C1-C15 stannane 72 . The construction of the $\mathrm{C} 1-\mathrm{C} 15$ stannane 72 commenced with an Evans syn aldo [56] with aldehyde $\mathbf{7 3}$ and $\mathbf{7 4}$ to generate adduct 75. ${ }^{[57]}$ Subsequent manipulations revealed aldehyde 76, which engaged with ketone ent-32 via a 1,4-syn boron-mediated aldol reaction ${ }^{[58]}$ to give 77 . Following protection, the final stereocentre was set through a diastereoselective reduction to generate fragment $\mathbf{7 8}$. The full $\mathrm{C} 1-\mathrm{C} 15$ stannane coupling partner $\mathbf{7 2}$ was then elaborated from $\mathbf{7 8}$ in five steps. Notably, the uniformly high diastereoselectivity of this route permitted the synthesis of both enantiomers of the $\mathrm{C} 1-\mathrm{C} 15$ fragment (72 and ent-72) required to probe the configurational relationship between the $\mathrm{C} 1-\mathrm{C} 15$ and the $\mathrm{C} 16-\mathrm{C} 24$ region.
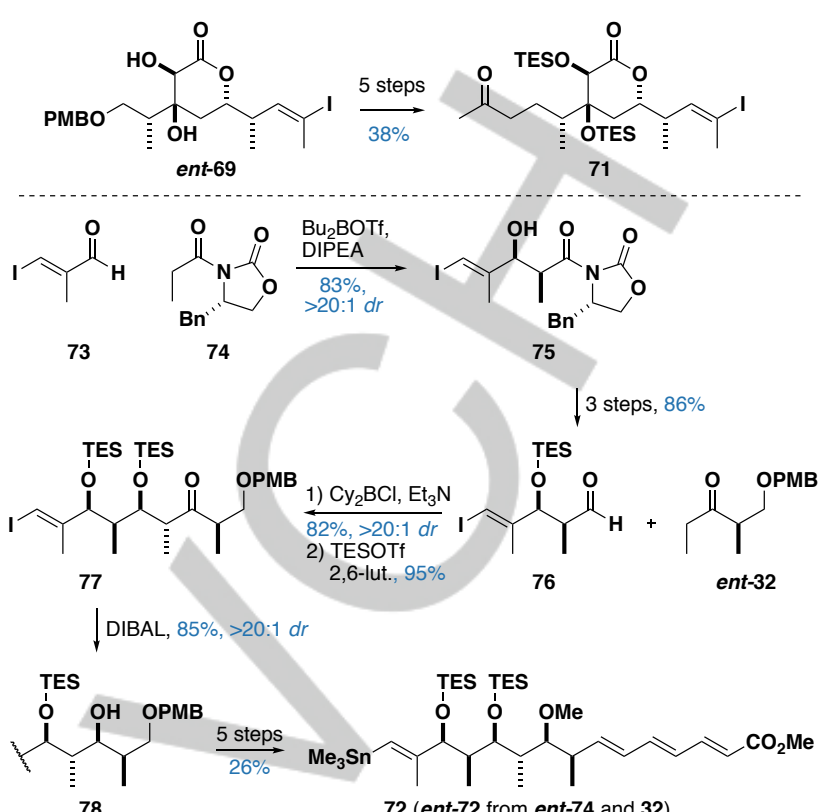

72 (ent-72 from ent-74 and 32$)$

Scheme 8 . Synthesis of vinyl iodide $\mathbf{7 1}$ and vinyl stannane $\mathbf{7 2}$

By coupling 71 with either $\mathbf{7 2}$ or ent-72, the 13,18-syn and 13,18-anti diastereomers 79a and 79b of the C1-C28 region were obtained (Scheme 9). These were then transformed into model acid truncates $80 \mathrm{a}$ and $80 \mathrm{~b}$. Detailed ${ }^{1} \mathrm{H}$ and ${ }^{13} \mathrm{C}$ NMR comparisons between $\mathbf{8 0 a}, \mathbf{8 0 b}$ with hemicalide revealed that the 13,18-syn configuration in $\mathbf{8 0}$ a was a much closer match than the alternative 13,18 -anti configuration in $\mathbf{8 0 b}$. This reduces the number of candidate stereoisomers to consider from over two million at the outset of this ambitious project down to 128 . This result demonstrates that NMR spectroscopic analyses of welldesigned synthetic truncates can discern between diastereomers possessing distally related stereoclusters that may otherwise be difficult to achieve via inferential means. Finally, it is worth noting that the combined Ardisson/Cossy/Meyer teams have recently prepared the partially deprotected full carbon skeleton of a diastereomer of hemicalide, bearing the incorrect 13,18-anti relationship, which resulted in a poor NMR spectroscopic correlation relative to the $\mathrm{C} 27-\mathrm{C} 32$ region of the natural product. ${ }^{[59]}$ In addition to the conclusions presented above, this gives credence to the idea that a wholly synthesis-based configurational elucidation of hemicalide is indeed possible.

\section{Summary and Outlook}

The continual advances in small molecule spectroscopic characterisation techniques have facilitated a much greater structural diversity of compounds to be isolated and elucidated from marine organisms. This, in turn, has inspired the development of state-of-the-art analytical methods on microscale, as well as novel synthetic methods for their de novo stereocontrolled construction. However, these contemporary analytical methods are not perfect and mistakes of interpretation 
still happen. In many cases, advanced techniques are unable to resolve stereochemical ambiguities, and a judicious synthetic chemistry campaign can still be used as the final tool to definitively pin down a novel compound's true identity.
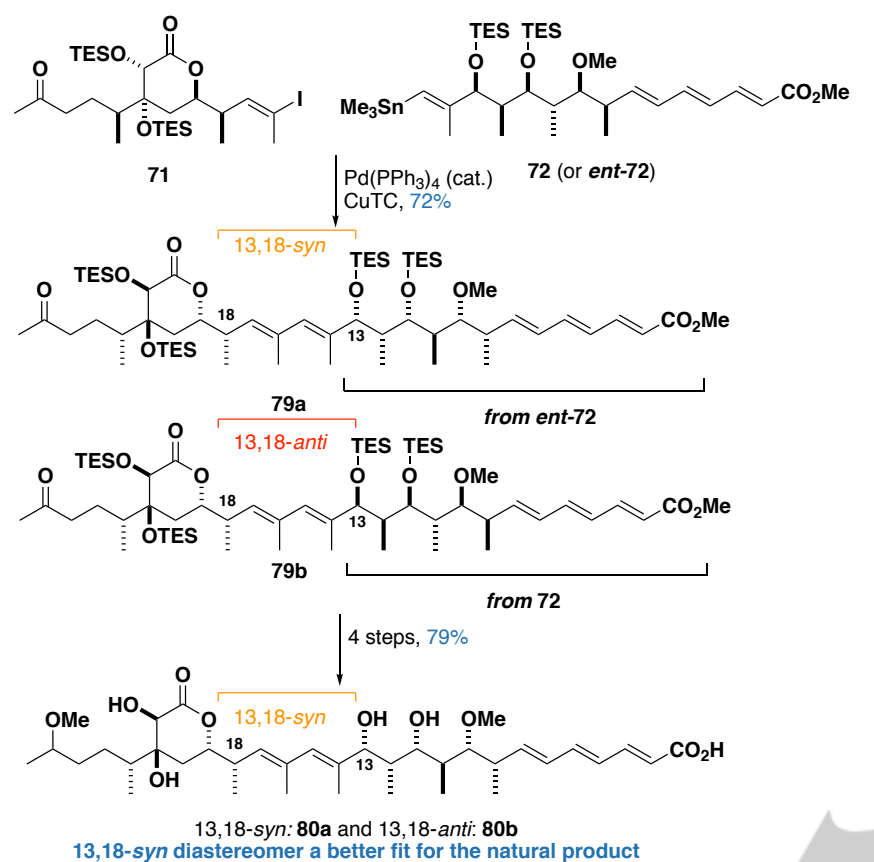

Scheme 9. The synthesis of model truncates $\mathbf{8 0 a}$ and $\mathbf{8 0 b}$ for NMR comparison resulted in the 13,18 -syn assignment between the $\mathrm{C} 1-\mathrm{C} 15$ region and the $\mathrm{C} 16-\mathrm{C} 24$ region

The aforementioned five detective stories from our own research $^{[60]}$ are among a multitude of examples in the chemical literature on the decisive role synthesis has played in the unambiguous stereochemical assignment of natural products. In cases where related natural products have been isolated, homology from biosynthetic proposals can guide a synthesisenabled reassignment, as evidenced by the reassignment of dolastatin 19 and dictyostatin. The recent advances in computational NMR methods was an enabling factor for our stereochemical assignment of leiodermatolide, which led to a manageable number of diastereomers to tackle in a focused total synthesis campaign. In the absence of other chemical or bioinformatic methods, the resulting total syntheses of (-)leiodermatolide also demonstrate the important role of enantiospecific synthesis in assigning the absolute configuration. The synthesis-enabled stereochemical reassignment of phormidolide A highlights the precarity of complex natural product structural elucidation. In the end, it was through the serendipitous stereochemical outcome of a pivotal vinyl Grignard aldehyde addition that led us to reassign seven of its 11 stereocentres. Finally, the complete lack of stereochemical information (and characterisation data!) available for hemicalide required a synergy of computational and synthetic approaches to incrementally illuminate its configuration. In this example, we demonstrated the power of computational NMR methods in elucidating the relative configuration within fragments. However, extending this method towards larger fragments proved impractical, and the ultimate proof-of-configuration in the C1-C28 region lay in its successful stereodefined synthesis. Echoing the example presented in leiodermatolide, detailed ${ }^{1} \mathrm{H}$ and ${ }^{13} \mathrm{C}$ NMR analysis of both diastereomers revealed distinct but small chemical shift differences for the 1,6-related stereoclusters. In the absence of crystallographic or microscopic techniques, being able to distinguish between distally related stereoclusters in flexible systems remains a feat that would be difficult to achieve, even with the most advanced characterisation methods available today.

The impact natural product chemistry has had on humanity is undeniable, and the relative infancy alongside some highprofile successes of marine natural products marks it as a fertile field for the continual discovery of promising new chemical entities as drug leads. With their ornate molecular architectures, as exemplified by phormidolide $A$ and hemicalide, their confident stereochemical elucidation will remain as an enduring challenge for practitioners in natural products research. On top of its further role of alleviating the supply problem presented by most marine natural products, organic synthesis offers a uniquely powerful tool for their stereochemical elucidation. It goes to show that the symbiotic relationship between synthetic organic and natural product chemistry will only serve to mutually benefit each other in our ongoing quest to find more effective disease-alleviating agents in improving the condition of humankind.

\section{Acknowledgments}

The work summarised in this Minireview was conducted by generations of highly able students and postdocs, whose dedication, creativity and hard work are gratefully acknowledged. We thank the Woolf Fisher Trust (scholarship to NYSL) for funding and Prof Rob Britton (SFU) for a productive collaboration on phormidolide $\mathrm{A}$.

Keywords: Aldol reaction • Polyketide • Total Synthesis • Natural Products $\bullet$ Stereocontrol

\section{References}

[1] T. L. Simmons, E. Andrianasolo, K. McPhail, P. Flatt, W. H. Gerwick, Mol. Cancer Ther. 2005, 4, 333-42.

[2] a) I. Paterson, E. Anderson, Science 2005, 310, 451-453. b) K.-S. Yeung, I. Paterson, Chem. Rev. 2005, 105, 4237-4313.

[3] G. M. Cragg, P. G. Grothaus, D. J. Newman, Chem. Rev. 2009, 109, 3012-43.

[4] a) D. J. Newman, G. M. Cragg, J. Nat. Prod. 2004, 67, 12161238. For a recent review of new marine natural products isolated, see: b) A. R. Carroll, B. R. Copp, R. A. Davis, R. A. Keyzers, M. R. Prinsep, Nat. Prod. Rep. 2019, 36, 122-173.

[5] T. F. Molinski, D. S. Dalisay, S. L. Lievens, J. P. Saludes, Nat. Rev. Drug Discov. 2009, 8, 69-85.

[6] D. J. Newman, G. M. Cragg, J. Nat. Prod. 2016, 79, 629- 
661.

R. D. Norcross, I. Paterson, Chem. Rev. 1995, 95, $2041-$ 2114.

[8] K. C. Nicolaou, S. A. Snyder, Angew. Chem. Int. Ed. 2005 44, 1012-1044

[9] R. T. Williamson, L. M. Brian, W. H. Gerwick, E. K. Katalin, Magn. Reson. Chem. 2000, 38, 265-273.

[10] N. Matsumori, D. Kaneno, M. Murata, H. Nakamura, K. Tachibana, J. Org. Chem. 1999, 64, 866-876.

[11] a) S. G. Smith, J. M. Goodman, J. Am. Chem. Soc. 2010 132, 12946-12959. A recent example of the limitations of the DP4 method is presented in: A. W. Phillips, M. J. Anketell, T. Balan, N. Y. S. Lam, S. Williams, I. Paterson, Org. Biomol. Chem. 2018, 16, 8286-8291

[12] C. G. Jones, M. W. Martynowycz, J. Hattne, T. J. Fulton, B. M. Stoltz, J. A. Rodriguez, H. M. Nelson, T. Gonen, ACS Cent. Sci. 2018, 4, 1587-1592.

[13] a) J. B. McAlpine, B. O. Bachmann, M. Piraee, S. Tremblay, A. M. Alarco, E. Zazopoulos, C. M. Farnet, J. Nat. Prod. 2005 68, 493-496. b) J. M. Winter, S. Behnken, C. Hertweck, Curr. Opin. Chem. Biol. 2011, 15, 22-31

[14] For recent examples of stereochemical assignments using gene sequence data, see: a) M. C. Kim, H. Machado, K. H. Jang, L. Trzoss, P. R. Jensen, W. Fenical, J. Am. Chem. Soc 2018, 140, 10775-10784. b) E. J. N. Helfrich, R. Ueoka, A Dolev, M. Rust, R. A. Meoded, A. Bhushan, G. Califano, R. Costa, M. Gugger, C. Steinbeck, P. Moreno, J. Piel, Nat Chem. Biol. 2019, 15, 813-821. A review on this topic is presented in: c) A. L. Harvey, R. Edrada-Ebel, R. J. Quinn, Nat. Rev. Drug Discov. 2015, 14, 111-129. Pioneering examples of using genetic data to assist in the absolute stereochemical elucidation of complex polyketides can be found in: d) D. Janssen, D. Albert, R. Jansen, R. Müller, M. Kalesse, Angew. Chem. Int. Ed. 2007, 46, 4898-4901. e) M. Bock, K. Buntin, R. Müller, A. Kirschning, Angew. Chem. Int. Ed. 2008, 47, 2308-2311.

[15] T. L. Suyama, W. H. Gerwick, K. L. McPhail, Bioorg. Med. Chem. 2011, 19, 6675-6701.

[16] S. J. Gould, N. Tamayo, C. R. Melville, M. C. Cone, J. Am. Chem. Soc. 1994, 116, 2207-2208.

[17] Y. Liu, J. Saurí, E. Mevers, M. W. Peczuh, H. Hiemstra, J. Clardy, G. E. Martin, R. T. Williamson, Science 2017, 356, DOI 10.1126/science.aam5349.

[18] a) T. R. Hoye, C. S. Jeffrey, F. Shao, Nat. Protoc. 2007, 2, 2451-2458. b) J. A. Dale, H. S. Mosher, J. Am. Chem. Soc. 1973, 95, 512-519.

[19] I. Paterson, R. D. M. Davies, R. Marquez, Angew. Chem. Int. Ed. 2001, 40, 603-607.

[20] B. M. Trost, J. L. Gunzner, O. Dirat, Y. H. Rhee, J. Am. Chem Soc. 2002, 124, 10396-10415.

[21] K. C. Nicolaou, T. V. Koftis, S. Vyskocil, G. Petrovic, W. Tang, M. O. Frederick, D. Y. K. Chen, Y. Li, T. Ling, Y. M. A. Yamada, J. Am. Chem. Soc. 2006, 128, 2859-2872.

[22] N. T. Kenton, D. Adu-Ampratwum, A. A. Okumu, P. McCarron, J. Kilcoyne, F. Rise, A. L. Wilkins, C. O. Miles, C. J. Forsyth, Angew. Chem. Int. Ed. 2018, 57, 810-813.

[23] For the Isolation report of dolastatin 19, see: a) G. R. Pettit, J. P. Xu, D. L. Doubek, J. C. Chapuis, J. M. Schmidt, J. Nat. Prod. 2004, 67, 1252-1255. For the structural elucidation of the aurisides, see: b) H. Sone, H. Kigoshi, K. Yamada, J. Org. Chem. 1996, 61, 8956-8960.

[24] a) I. Paterson, A. D. Findlay, G. J. Florence, Tetrahedron 2007, 63, 5806-5819. b) I. Paterson, A. D. Findlay, Pure Appl. Chem. 2008, 80, 1773-1782.

[25] I. Paterson, A. D. Findlay, G. J. Florence, Org. Lett. 2006, 8, 2131-2134.

[26] I. Paterson, J. M. Goodman, M. A. Lister, R. C. Schumann, C. K. McClure, R. D. Norcross, Tetrahedron 1990, 46, 46634684.

[27] G. R. Pettit, Z. A. Cichacz, F. Gao, M. R. Boyd, J. M. Schmidt, J. Chem. Soc. Chem. Commun. 1994, 0, 1111-1112.

[28] I. Paterson, R. Britton, O. Delgado, A. E. Wright, Chem. Commun. 2004, 632.

[29] A. G. Myers, B. H. Yang, H. Chen, L. McKinstry, D. J. Kopecky, J. L. Gleason, J. Am. Chem. Soc. 1997, 119, 6496-6511.

[30] I. Paterson, R. Britton, O. Delgado, A. Meyer, K. G. Poullennec, Angew. Chem. Int. Ed. 2004, 116, 4729-4733.

[31] W. C. Still, C. Gennari, Tetrahedron Lett. 1983, 24, 44054408.

[32] H. C. Brown, K. S. Bhat, J. Am. Chem. Soc. 1986, 108, 5919-5923.

[33] Y. Shin, J. H. Fournier, Y. Fukui, A. M. Brückner, D. P. Curran, Angew. Chem. Int. Ed. 2004, 43, 4634-4637.

[34] a) S. M. Dalby, I. Paterson, Curr. Opin. Drug Discov. Devel. 2010, 13, 777-794. b) I. Paterson, G. J. Naylor, N. M. Gardner, E. Guzmán, A. E. Wright, Chem. Asian J. 2011, 6 , 459-473.

[35] a) K. R. Brunden, N. M. Gardner, M. J. James, Y. Yao, J. Q. Trojanowski, V. M.-Y. Lee, I. Paterson, C. Ballatore, A. B. Smith, ACS Med. Chem. Lett. 2013, 4, 886-889. b) V. Makani, B. Zhang, H. Han, Y. Yao, P. Lassalas, K. Lou, I. Paterson, V. M. Y. Lee, J. Q. Trojanowski, C. Ballatore, et al. Acta Neuropathol. Commun. 2016, 4, 106.

[36] A. E. Wright, J. K. Reed, J. Roberts, R. E. Longley, Antiproliferative Activity of the Leiodermatolide Class of Macrolides. U.S. Pat. Appl. Publ. (USA), US2008033035.

[37] I. Paterson, S. M. Dalby, J. C. Roberts, G. J. Naylor, E. A. Guzmán, R. Isbrucker, T. P. Pitts, P. Linley, D. Divlianska, J. K. Reed, et al., Angew. Chem. Int. Ed. 2011, 50, 3219-3223.

[38] I. Paterson, T. Paquet, S. M. Dalby, Org. Lett. 2011, 13, $4398-4401$.

[39] I. Paterson, M. A. Lister, Tetrahedron Lett. 1988, 29, 585588.

[40] D. A. Evans, A. H. Hoveyda, J. Am. Chem. Soc. 1990, 112, 6447-6449.

[41] I. Paterson, S. Williams, Isr. J. Chem. 2017, 57, 192-201.

[42] J. Willwacher, N. Kausch-Busies, A. Fürstner, Angew. Chem. Int. Ed. 2012, 51, 12041-12046.

[43] I. Paterson, K. K.-H. Ng, S. Williams, D. C. Millican, S. M. Dalby, Angew. Chem. Int. Ed. 2014, 53, 2692-2695.

[44] R. T. Williamson, A. Boulanger, A. Vulpanovici, M. A. Roberts, W. H. Gerwick, J. Org. Chem. 2002, 67, 7927-7936.

[45] M. J. Bertin, A. Vulpanovici, E. A. Monroe, A. Korobeynikov, D. H. Sherman, L. Gerwick, W. H. Gerwick, ChemBioChem 
2016, 17, 164-173.

[46] N. Y. S. Lam, G. Muir, V. R. Challa, R. Britton, I. Paterson, Chem. Commun. 2019, 55, 9717-9720.

[47] S. Kiyooka, M. A. Hena, J. Org. Chem. 1999, 64, 5511-5523.

[48] M. Bergeron-Brlek, T. Teoh, R. Britton, Org. Lett. 2013, 15, 3554-3557.

[49] S. D. Rychnovsky, B. Rogers, G. Yang, J. Org. Chem. 1993 58, 3511-3515.

[50] J. Wu, P. Lorenzo, S. Zhong, M. Ali, C. P. Butts, E. L. Myers, V. K. Aggarwal, Nature 2017, 547, 436-440.

[51] I. Carletti, C. Debitus, G. Massiot, Molécules Polykétides Comme Agents Anticancéreux. WO2011051380 (A1). 2011

[52] E. Fleury, M.-I. Lannou, O. Bistri, F. Sautel, G. Massiot, A. Pancrazi, J. Ardisson, J. Org. Chem. 2009, 74, 7034-45.

[53] E. Fleury, G. Sorin, E. Prost, A. Pancrazi, F. Sautel, G. Massiot, M.-I. Lannou, J. Ardisson, J. Org. Chem. 2013, 78, 855-64.

[54] S. Specklin, G. Boissonnat, C. Lecourt, G. Sorin, M.-I. Lannou, J. Ardisson, F. Sautel, G. Massiot, C. Meyer, J.
Cossy, Org. Lett. 2015, 17, 2446-9.

[55] C. I. MacGregor, B. Y. Han, J. M. Goodman, I. Paterson, Chem. Commun. 2016, 52, 4632-5.

[56] D. A. Evans, J. Bartroli, T. L. Shih, J. Am. Chem. Soc. 1981 103, 2127-2129.

[57] B. Y. Han, N. Y. S. Lam, C. I. MacGregor, J. M. Goodman, I. Paterson, Chem. Commun. 2018, 54, 3247-3250.

[58] I. Paterson, G. J. Florence, K. Gerlach, J. P. Scott, N. Sereinig, J. Am. Chem. Soc. 2001, 123, 9535-9544.

[59] C. Lecourt, S. Dhambri, K. Yamani, G. Boissonnat, S. Specklin, E. Fleury, K. Hammad, E. Auclair, S. Sablé, A. Grondin, et al., Chem. Eur. J. 2019, 25, 2745-2749.

[60] For representative recent work from our group, see: a) I. Paterson, N. Y. S. Lam, J. Antibiot. 2017, 71, 215-233. b) N. Anžiček, S. Williams, M. P. Housden, I. Paterson, Org. Biomol. Chem. 2018, 16, 1343-1350. 
WILEY-VCH

\section{MINIREVIEW}

Through the judicious use of stereocontrolled transformations in combination with detailed experimental and computational NMR studies, this Minireview highlights recent synthetic work on stereochemically ambiguous marine polyketide natural products that has resulted in their configurational assignments and reassignments.

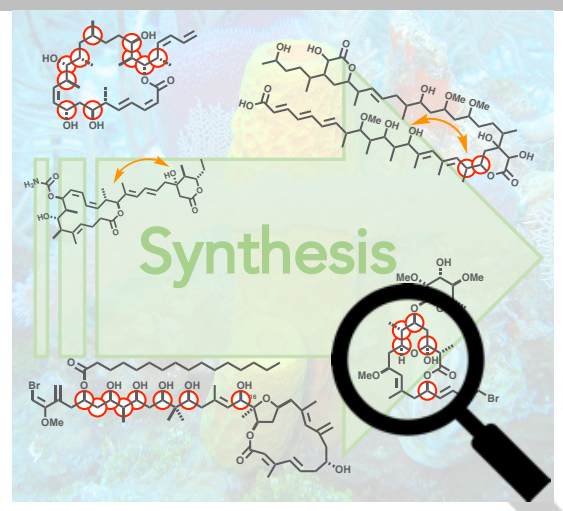

Total synthesis, Polyketides*

Nelson Y. S. Lam, Ian Paterson*

Page No. - Page No.

Stereocontrolled synthesis as an enabling tool for the configurational assignment of marine polyketide natural products

*one or two words that highlight the emphasis of the paper or the field of the study

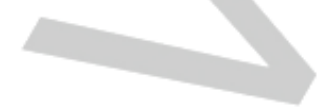

